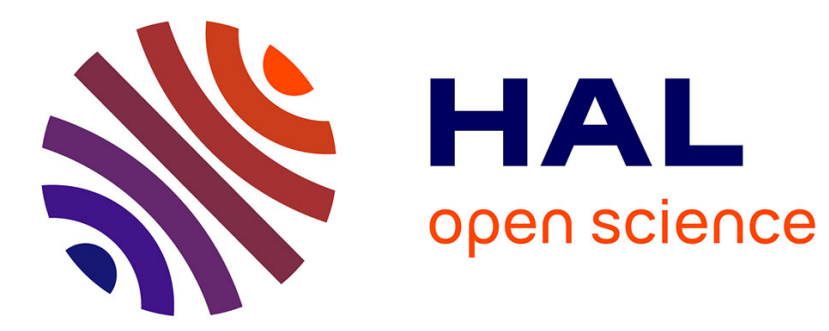

\title{
Lessons From HIV-1 Gene Therapy in Humanized Mice: Is Targeting Viral Entry the Road to Success?
}

\author{
Nicolas Petit, Gilles Marodon
}

\section{To cite this version:}

Nicolas Petit, Gilles Marodon. Lessons From HIV-1 Gene Therapy in Humanized Mice: Is Targeting Viral Entry the Road to Success?. Current Gene Therapy, 2016, 16 (1), pp.56-64. 10.2174/1566523216666160104141644 . hal-01318100

\section{HAL Id: hal-01318100 \\ https://hal.sorbonne-universite.fr/hal-01318100}

Submitted on 19 May 2016

HAL is a multi-disciplinary open access archive for the deposit and dissemination of scientific research documents, whether they are published or not. The documents may come from teaching and research institutions in France or abroad, or from public or private research centers.
L'archive ouverte pluridisciplinaire HAL, est destinée au dépôt et à la diffusion de documents scientifiques de niveau recherche, publiés ou non, émanant des établissements d'enseignement et de recherche français ou étrangers, des laboratoires publics ou privés. 


\section{Lessons from HIV-1 gene therapy in humanized mice: is targeting viral entry the road to success?}

Nicolas Petit and Gilles Marodon

Sorbonne Universités, UPMC Univ Paris 06, CR7, INSERM, CNRS, Centre d'Immunologie et des Maladies Infectieuses (CIMI -PARIS), Paris, France

corresponding authors: nicolas.petit1984@gmail.com, gilles.marodon@upmc.fr 


\section{Summary}

Immunodeficient mice reconstituted with human $\mathrm{CD}^{+} \mathrm{T}$ cells, which can be achieved either by transfer of mature cells or immature progenitors, represent the only animal model to study HIV-1 infection of human lymphocytes in vivo. However, the immunocompromised status of most of these models currently rule out their use for vaccine studies. Nevertheless, the model might be ideally suited for HIV-1 gene therapy studies since eliciting an efficient anti-viral immune response is not the primary end-point. Rather, HIV-1 gene therapy should protect $\mathrm{CD}^{+}{ }^{+} \mathrm{T}$ cells from HIV-1-induced deletion and/or reduced viral replication. Here, we describe recent advancements in the field of HIV-1 gene therapy, focusing on tools and targets validated in various models of humanized mice. From the analysis of this literature, it appears that strategies targeting viral entry, by means of neutralizing antibodies or fusion inhibitors, are the most promising so far. Indeed, strategies targeting viral entry have moved to the clinic with encouraging results. Thus, humanized mice should be considered as the prime model to devise the safer and most effective HIV-1 gene therapy strategy. 


\section{Introduction}

Animal models are crucial to test novel therapeutic strategies in pre-clinical studies. However, only humans and chimpanzees are susceptible to Human Immunodeficiency Virus type 1 (HIV-1) infection, greatly limiting the possibilities for in vivo experimental studies. To bypass the limitation of pre-clinical studies in monkeys or humans, researchers developed small animal models of HIV-1 infection, trying to mimic the human pathology as close as possible. However, it is a daunting, if not impossible, task to recapitulate all of the complex interplay between HIV-1 and human $\mathrm{CD}^{+} \mathrm{T}$ lymphocytes in a single animal model. Most of the informations gathered on HIV-1 in non-human primates (NHP) comes from the extrapolation of results obtained with chimeric SIV harboring the HIV-1 envelope or from SIV itself. Although SIV infection might present key features of the human clinical picture in certain conditions, it must be remembered that SIV infection is nonpathogenic in its natural host. Furthermore, several molecular evidences show that SIV doesn't behave the same way in a NHP lymphocyte than HIV-1 in a human one. It is quite expected if one consider that SIV is a distant ancester of HIV-1. Thus, there are strong limitations in the use of NHP models to study HIV-1 infection per se.

To build a model closer to the human physiopathology, various methods have been employed in various species, rat, rabbit or mouse. To sum-up decades-long research in one sentence, immunodeficient mice transplanted with human cells is the only animal model susceptible to HIV-1 infection that recapitulates high levels of viral replication, and in which a profound and steady HIV-dependent human $\mathrm{CD}^{+} \mathrm{T}$ cell deletion can be observed $[1,2] \square$. Several versions of humanized mice (HuMice) are available depending on their degree of immunodeficiency or genetic background. However, most of the current models of HuMice are severely hampered in the competency of the human immune system they carry, notably by the well recognized defect in T-B crosstalk in germinal centers, preventing efficient generation of IgG antibodies. This defect has 
hampered vaccine studies in most HuMice models. In contrast, HuMice might represent the best model for testing and validating HIV-1 gene therapy strategies, the ultimate aim of which being to prevent de novo infection of human $\mathrm{CD}^{+} \mathrm{T}$ lymphocytes [3] $\square$, an easy biological parameter to assess. Here, we will focus on HIV-1 gene therapy studies using HuMice, highlighting some interests of the model and discussing some limitations as well. The development of HuMice models for retroviral studies and for gene therapy applications have been the subject of recent reviews $[4,5] \square$ and will not be extensively discussed here. For detailed information on molecular processes affected by gene therapy targeting the virus, please refer to the review of Nazari et al. [6] $\square$. We summarized in a table the most common immunodeficient mice strains currently used for gene therapy of HIV-1 infection (Table 1). For sake of simplicity and convenience, a table gathering the most significant findings on the efficacy of HIV-1 gene therapy in HuMice is also given (Table 2). The choice of the references is subjective. We apologize to all authors whom studies are not cited. 


\section{Humanization of immunodeficient mice}

The development of HuMice began in the late 1980s with the publication of two articles on the study of development and differentiation of human cells in vivo $[7,8] \square$. These studies were performed in the CB-17 SCID genetic background. The Prkdc ${ }^{\text {scid }}$ mutation concerns a protein kinase involved in the DNA repair mechanism during the recombination of heavy and light chains of immunoglobulin and $\mathrm{T}$ cell receptor, leading to the complete absence of $\mathrm{T}$ and $\mathrm{B}$ cells in these animals. Recombination of the $\mathrm{T}$ and $\mathrm{B}$ cell receptor is also executed in part by the RAG-1 and RAG-2 genes (Recombination Activating Gene) and their deletion induce a similar phenotype than the SCID mutation that is a complete lack of T and B cells in genetically deficient animals $[9,10] \square$. While it was very difficult in those mice to observe final maturation of human $\mathrm{T}$ cells from progenitors, addition of the $\gamma c$ chain gene (CD132) deficiency has significantly advanced the extent of humanization [11] $\square$. The $\gamma \mathrm{c}$ mutation associated with SCID or RAG mutations generates double "knock-outs" (DKO) profoundly immunodeficient, devoid of murine T, B and NK cells. These DKO mice exist in various genetic backgrounds (Table 1) but only the NOD (NSG [12] $\square$ or NOG $[11] \square$ ) or BALB/c background (BRG [13] $\square$ ) allows efficient generation of human $\mathrm{T}$ cells from progenitors. Later the SCID mutation in NSG was replaced by the RAG mutation, conferring a better resitance of these NRG mice to irradiation [14] $\square$. The Triple KO model (TKO), made only in a C57BL/6 genetic background, carries an additional mutation in the CD47 murine gene [15] $\square$. This ubiquitous molecule interacts with the polymorphic SIRP $\alpha$ protein (SIgnal Regulatory Protein alpha) only expressed on macrophages, dendritic cells and neutrophils. The engagement of CD47 inhibits phagocytosis, the 'do not eat me' signal [16] $\square$. The DKO mice in the C57BL/6 genetic background have a low potential of hematopoietic reconstitution which was directly attributed to a lack of interaction between the human and murine CD47/ SIRP $\alpha[17,18] \square$. However, DKO mice on a NOD background have good human cell engraftment because the murine SIRP $\alpha$ of this 
background can naturally interact with the human CD47 molecule. Some improvements in human cell reconstitution of BRG mice have been obtained by introducing the human SIRP $\alpha$ [19] $\square$ in transgenic mice or the human CD47 molecule on hematopoetic progenitors [20] $\square$. Overall, it appears that the quality of hematopoietic reconstitution in immunodeficient mice varies greatly from one genetic background to another. In order of effectiveness, the NOD background is greater than the BALB/c background, itself greater than the C57BL/6 background, the TKO and BRGS models aside.

\section{Humanized mice and HIV-1 infection}

There are different type of HuMice depending on the type of tissues and/or cells used. Historically, the first humanized mice were generated by human PBMC transplantation. This model has the advantage of being easy to produce and quickly generate activated $\mathrm{T}$ lymphocytes few days post-transplant. These cells spread throughout the body and are found in the bone marrow, liver, lung and spleen [21] $\square$. In addition, these mice are able to mount a cytotoxic $\mathrm{T}$ cell response sufficient to induce skin graft rejection [22] $\square$. However, this model suffers from a major drawback since the transferred human cells are also able to mount a response against host tissues to provoke a xenogeneic graft-versus-host disease (xeno-GVHD) [21] $\square$. Xeno-GVHD causes death within a few weeks after transplant, imposing a short window for HIV-1 studies. Nevertheless, this model was one of the first HuMice model used to study HIV (in NS mouse). A massive CD4 T lymphocyte deletion correlated with a strong increase in the viral load [23] $\square$. The PBMC mice model was subsequently reproduced in more advanced genetic backgrounds: NSG or DKO but with similar problems of xeno-GVHD [5] $\square$.

A second approach to generate HuMice consists in the transplantation of human hematopoietic progenitors associated with a pre-transplant conditioning, total body irradiation or 
alkylating agent injection (such as busulfan). The above models support the graft and differentiation of human Hematopoietic Stem Cells (HSC) contained in the fraction of CD $34^{+}$cells bone marrow, cord blood or fetal liver. T cell development is usually observed between 3-4 months post transplant [11-13] $\square$. Importantly, these $\mathrm{T}$ cells carried a diverse immune repertoire, allowing a weak but detectable antigen-specific cellular immune response [24] $\square$. In the thymus of these mice, all immature and mature lineages of human thymocytes were observed [24] $\square$, suggesting that positive selection of human TCR on murine MHC molecules was taking place. The extent of this selection is however very limited since the numbers of human thymocytes found in the murine thymus is generally 1/100th of a normal murine thymus, suggesting an inefficient cross reactivity between human TCRs and murine MHCs.

NSG, NOG and NRG genetic background grafted with human HSCs are three very similar models. These models have a low level of humanization in the intestinal or vaginal mucosa and thus, are probably not susceptible to infection by these routes. However, after intraperitoneal or intravenous HIV-1 injection, $\mathrm{CD}^{+}{ }^{+} \mathrm{T}$ cell deletion is observed in the periphery that correlated with an increase in viral load [25-27] $\square$. After the peak, resolution of the viral load to a set point, as observed in humans, has not been consistently found: HIV-specific CD8 ${ }^{+}$T cells may [28] $\square$ or may not $[29] \square$ be responsible for viral control in the early phase of the infection. In two studies, BRG mice could be infected by HIV-1 via the vaginal or rectal routes that causes $\mathrm{CD}^{+}{ }^{+}$Tymphocyte deletion [30-32] $\square \square$. However, an additional study did not confirm this finding [33] $\square$. Thus, the current route to infect HuMice is mostly through intravenous or intraperitoneal injections. This is a limitation of current models that must be taken into account when devising gene therapy strategies.

The most advanced model of humanization is the BLT (Bone Liver Thymus) model developed in parallel by two teams in 2006, based on the initial work of McCune [7] $\square$. BLT mice were generated by fetal liver and fetal thymus transplants associated with human HSC grafted into 
the NS [34,35] $\square \square$ background. This protocol significantly improves hematopoietic reconstitution of human cells compared to NSG, NOG or BRG models grafted with human PBMC or HSC alone. These mice also have the advantage of carrying a fully functional immune system. Indeed, they are able to mount effector responses associated with cytokine secretion and a high production of $\operatorname{IgG}$ antibodies [15,34-36] $\square$. This good functionality comes at the expense of longevity since BLT mice might suffer from xeno-GVHD from the twelfth week post-reconstitution correlated with mortality to the fifteenth week [37] $\square$. However, BLT mice made in the TKO background had no symptoms of GVHD even 29 weeks post-transplantation, although a very good hematopoietic reconstitution was observed in the blood, spleen, mesenteric lymph nodes and in tissues such as the intestine [15] $\square$. BLT model generated in the NS, NSG, or TKO background, has very good engraftment in the gut, the vagina and the small intestine favoring HIV-1 infection via the mucous membranes (reviewed in [38] $\square$ ). In addition, the increase in viral load correlates with $\mathrm{CD}^{+} \mathrm{T}$ cell deletion in peripheral blood, intestine, colon and mesenteric lymph nodes. Thus, BLT appears as the best model so far to study HIV-1 infection of its natural host, human $\mathrm{CD}^{+} \mathrm{T}$ cells. However, technical and logistical difficulties, as well as costs and ethical issues, issues that are beyond the scope of the present review, still render this model difficult to set up in average research laboratories.

\section{Gene therapy of HIV-1 infection in humanized mice}

The main goal of HIV-1 gene therapy is to generate $\mathrm{CD}^{+} \mathrm{T}$ cells resistant to infection by targeting viral or human proteins involved at various stages of the viral cycle. These can act at the level of viral entry, pre-integration and post-integration stages of the infection or they can also target mature virions or infected cells directly. All of these stages have been well evaluated in vitro, but fewer studies have been conducted in vivo in HuMice. This chapter will attempt to provide the reader with a list of the main findings gathered in various models of HuMice according to the stage 
of infection that was targeted (Table 2).

\section{Targeting viral entry}

During primo-infection, HIV-1 uses the CD4 receptor and the coreceptor CCR5 to infect human memory/activated/follicular helper $\mathrm{CD}^{+} \mathrm{T}$ cells. The CD4 molecule plays an important role in the immune system and altering its expression would not be without risk. However, in the 1990s, soluble CD4 molecules have been used as decoys to trap HIV-1 before infection. These molecules have shown good efficacy in vitro but have proved ineffective in patients [39] $\square$. Recently, a new chimeric molecule based on CD4-Ig and a small mimetic of CCR5 was developed and encoded in an Adeno-Associated Virus (AAV) gene transfer vector. This virus completely protected NSG HuMice from HIV-1 infection and monkeys from SIV [40] $\square$. This promising result highlights the importance of targeting entry for efficient prevention.

Besides CD4, the CCR5 co-receptor is indeed a good target for gene therapy because individuals who carrying the $\Delta 32$ mutation are not affected by major immunological disorders (although they may be more sensitive to complications of West Nile virus infection [41] $\square$ ) but are highly resistant to HIV infection [42] $\square$. In addition, infected patients treated with Maraviroc, an allosteric inhibitor of gp120-CCR5 interaction, present lower viral loads and a surge in CD4 T cells counts in blood without exhibiting immune side effects [43] $\square$. Finally, the therapeutic success of the Berlin patient show that CCR5 is the only target so far that has the potential to cure HIV infection in an infected person $[44,45] \square$. The goal of gene therapy strategies targeting this molecule is to reproduce the phenotype of $\Delta 32$ individuals and of the Berlin patient, that is preventing expression of CCR5 from $\mathrm{CD}^{+} \mathrm{T}$ cell surface. Numerous approaches are possible to decrease expression of CCR5, by directly targeting the CCR5 gene at the DNA level, the mRNA encoding CCR5 or the protein itself. 
Targeting the CCR5 gene with DNA editing enzymes

The CCR5 gene can be directly targeted using Zinc Finger Nucleases (ZFNs) or TALEN to permanently ablate its expression. ZFNs have the properties to recognize a specific DNA sequence via the zinc finger and cleaved DNA by the FokI endonuclease. The efficacy of ZFNs was elegantly demonstrated by targeting the human CCR5 gene in ex vivo modified human cells [46,47]. Those modifed cells were subsequently grafted in NSG or NOG mice to show a stable CD4 / CD8 ratio in the blood after HIV infection. Moreover, mice were protected against $\mathrm{CD}^{+} \mathrm{T}$ cell deletion in different tissues (spleen, bone marrow, thymus and intestine). There was also a selective advantage for modified cells over non-modified cells in the blood and this was accompanied by reduced viral loads. Of note is that transient expression of the ZFN using non-integrated lentiviral vectors allowed the same degree of efficacy in NSG mice reconstituted with modified T cells [48] $\square$. Targeting the CCR5 coreceptor may cause selective pressure on the virus and favor the emergence of CXCR4tropic viruses, more pathogenic than CCR5-tropic viruses. Studies using ZFNs targeting the CXCR4 coreceptor also demonstrated good efficacy against viral replication for viruses using CXCR4 in NSG PBL HuMice $[49,50] \square$. To our knowledge, there are no studies published yet using CCR5 TALEN or CCR5 CRISPR/ Cas9 in HuMice. However, in vitro studies showed a selective advantage for $\mathrm{T}$ lymphocytes transfected with CCR5 TALEN [51] $\square$ and a decrease in viral replication in a cell line disrupted for the CCR5 gene with CRISPR/ Cas9 system [52] $\square$. It is very likely that some studies in HuMice will use this technology in the near future. Although extremely promising, the exact impact of permanent CCR5 genetic ablation in HSC, notably on cell migration and resolution of inflammation, remains to be investigated.

A very original approach used peptide nucleic acids (PNA) directed site-specific recombination of the CCR5 gene. Binding of these peptides to DNA forms a triplex structure that 
induce recombination and introduce inactivating mutations [53] $\square$. This strategy was used in HuMice to show that modifled PBMC were protected from HIV-1-induced deletion that corrrelated with lower viral loads [54] $\square$. Of note is that study was performed with $\Delta 32$-heterozygous PBMCs since this might have played a role in the success of the strategy. Future results in a clinical trial will tell whether this enzyme-free strategy migh be useful compared to the ones using DNA-editing enzymes.

Targeting the CCR5 RNA with RNA

CCR5 expression can also be altered by RNA interference (RNAi). RNAi is a posttranscriptional mechanism of gene regulation that targets the mRNA with microRNA (miRNA), small interfering RNA (siRNA) or RNA hairpin (shRNA). The interaction between these RNA and mRNA results in the degradation of the mRNA, or to block protein translation. This system has been used to target CCR5 expression. A decrease of coreceptor expression on the cell surface was correlated to a decrease in viral replication in vitro [55] $\square$. In HuMice, injection of a CCR5 siRNA formulated in nanoparticles induced a decrease in expression of CCR5 on the cell surface and preserved the CD4/CD8 ratio in the infected animals. There was also a decrease in viral replication in BLT mice [56] $\square$. However, these effects were not long lasting since there was no integration of the siRNA into the genomic host. To improve efficiency, siRNA have been included into lentiviral vectors, allowing long term expression. Transduction of human $\mathrm{CD}^{+} 4^{+}$cells with a CCR5 shRNA did not affect hematopoiesis and cell migration when they were grafted into BLT mice. Moreover, splenocytes expressing low levels of CCR5 were less susceptible to an ex vivo challenge by HIV-1 [57] $\square$. Recently, Dr Speck's team has modified CD34+ cells with a lentiviral vector which allow coexpression of GFP and of a CCR5 miRNA. CD $34^{+} \mathrm{GFP}^{+}$were sorted and grafted into NSG mice. After infection with an R5-tropic HIV-1, these mice had a lower viral load, a higher $\mathrm{CD}^{+}{ }^{+}$cell 
frequency and a higher CD4/CD8 ratio in blood and spleen than control mice [58] $\square$. Very similar results were obtained in BLT mice [59] $\square$.

\section{Targeting the CCR5 protein}

Another approach to reduce CCR5 expression is to target the protein directly. Various strategies can be used, the first being based on the intrinsic properties of antibodies to specifically recognize a protein. A transgene encoding an antibody directed against the $\mathrm{N}$-terminal portion of CCR5 was coupled to a retention sequence in the endoplasmic reticulum (ER) called KDEL, defining the 'intrabody' strategy. This construction captures and sequesters the coreceptor in the ER and induces a decrease of expression at the cell surface. $\mathrm{CD} 4^{+} \mathrm{T}$ carrying this intrabody were more resistant to HIV-1 infection and had a selective advantage in vivo in BLT mice [60] $\square$. A second strategy is based on the use of a high affinity CCL5 mutant (P2-CCL5), developed by the team of Pr Gorochov [61] $\square$. We showed that P2-CCL5 incorporating the KDEL sequence was able to down regulate CCR5 expression from the cell surface of primary cells in vitro [62] $\square$. However, the impact on HIV-1 replication was limited, suggesting that modulating CCR5 expression from the cell surface by this technology was not enough to protect $\mathrm{CD}^{+} \mathrm{T}$ cells against HIV-1 infection. A subsequent study of ours showed that combining P2-CCL5 with a fusion inhibitor dramatically enhanced the anti-HIV-1 efficacy in HuMice (see below) [63] $\square$.

Targeting fusion with gp41 peptides

A small peptide called Enfurvitide (T20/C36), a gp41 analog that can compete with gp41 of the virus and block its folding, was shown to be very effective in preventing viral infection [64] $\square$. This molecule has demonstrated clinical effectiveness and was the first fusion inhibitor to be 
administered to patients [64] $\square$. Pr. Von Laer's team has vectorized the C36 peptide and added 10 amino-acids at the $\mathrm{N}$-terminus of the pepide to decrease the risk of resistant mutants. Addition of a transmembrane sequence domain allows its stable expression on the cell surface. This new construct called C46 confers a high level of resistance to HIV infection [65] $\square$ and a selective advantage for expressing $\mathrm{CD}^{+} \mathrm{T}$ cells in vivo [66] $\square$. Thus, combining the $\mathrm{C} 46$ peptide with CCR5 inhibitors might be a promising combination for HIV-1 gene therapy (see below).

\section{Targeting decapsidation, pre- and post-integration}

Evolution has endowed human cells with natural defenses against lentiviruses. Some human proteins referred to as restriction factors, inhibits different steps of the viral cycle. However, most of the human restriction factors are inhibited by HIV-1 proteins. The alpha isoform of the Tripartite motif-containing 5 (TRIM5 $\alpha$ ) protein identified in rhesus macaques (rhTRIM5 $\alpha$ ) has anti-HIV-1 properties, explaining most of the resistance of these monkeys to the virus [67] $\square$. Although not fully elucidated, rhTRIM5 $\alpha$ seems to interfere with the uncoating of the viral capsid, thereby preventing efficient reverse transcription [68] $\square$. The human version of TRIM5 $\alpha$ (hTRIM5 $\alpha$ ) is ineffective against HIV-1 and was modified to result in the formation of a chimeric version of $\mathrm{h}$ rhTRIM5 $\alpha$, allowing a better immune tolerance to this protein. This chimera, slightly less effective than the monkey version, still confers protection to HIV-1. Indeed, in vitro and ex vivo experiments show that cells expressing the transgene become majority and that viral replication was lower than in control conditions [69] $\square$.

The Lens Epithelium-Derived Growth Factor p75 (LEDGF/p75) is a cellular protein that plays an essential role in HIV-1 infection. This ubiquitous protein allows interaction between human cell chromatin and HIV integrase and integration of the provirus into cell DNA. It has been demonstrated that cells deficient in this molecule became resistant to infection [70] $\square$, making it a 
potential target for gene therapy. In NSG mice, results show that a lentiviral vector encoding a modified version of LEDGF/p75 competing with the endogenous protein for binding to the integrase of HIV, conferred protection from infection to $\mathrm{CD}^{+} \mathrm{T}$ lymphocytes in blood and lowered plasma viral loads [71] $\square$.

\section{Targeting provirus transcription}

Viral RNAs can be degraded by catalytic RNA called ribozymes, as well as by shRNA or siRNA. One strategy using siRNA to target nef showed that modified cells from BRG mice were somehow resistant to HIV-1 infection ex vivo [72] $\square$. However, these approaches suffer from rapid emergence of escape variants. One possibility to limit this escape would be to combine various siRNA [73] $\square$. A unique approach targeting the LTR of integrated provirus with a specific Tre recombinase, derived from molecular evolution of the bacteriophage Cre recombinase [74] $\square$, showed a decrease in viral load associated to a protection against deletion in BRG mice grafted with transduced PBMC or modified $\mathrm{CD}^{+} 4^{+}$progenitors [75] $\square$. In this study, 10 out of 11 mice presented a decrease in their viral loads whereas control mice had increased or stable viral loads. Provirus was also targeted in vitro by CRISPR/Cas9 or by TALEN $[76,77] \square$. The efficacy of this strategy remains to be investigated in vivo in HuMice. However, lethal effects of HIV-1 on CD4 ${ }^{+} \mathrm{T}_{\text {cells }}$ might take place before integration [78] $\square$, casting doubts on the interest of targeting proviruses to protect $\mathrm{CD}^{+} \mathrm{T}$ cells from deletion.

\section{Targeting mature virions by passive immunization with gene therapy}

Inducing an effective antibody response against HIV-1 is complex and remains the main purpose of vaccination strategies. However, results regarding an efficient HIV-1 vaccine are so far 
disappointing. Passive immunization strategies infusing broadly neutralizing antibodies (bnAbs) may overcome several hurdles of HIV-1 vaccine development. Injection of a single $\mathrm{nAb}$ or of a combination of bnAbs prevented HIV-1 infection in NRG HuMice $[79,80] \square$. However, antibody injections do not maintain immunity in serum and mucous tissues for a long period. Gene transfer strategies may help inducing a stable expression of nAbs. HIV-1 in vivo challenge experiments showed a highly attenuated viral replication and protection against deletion in HuMice models expressing the humanized $\mathrm{Ab}[81-85] \square$. In the studies of Balazs et al., a single $\mathrm{nAb}$ was vectorized in an AAV vector and injected intramuscularly into NSG-BLT HuMice. This protocol allowed the production of hundreds of micrograms $/ \mathrm{mL}$ of antibodies for a full year. In addition, the same stability of expression of antibodies was observed in immunodeficient (NSG, BRG) or immunocompetent mice (C57BL/6, BALB/c). In immunocompetent mice, the protocol induced a weak production of murine Abs directed to the vector-encoded nAbs, without decreasing their production. Importantly, this sustained expression protected HuMice from intravaginal HIV-1 infection. These results further highlight the efficacy of strategies preventing viral entry.

\section{Targeting infected cells by TCR gene transfer}

Other approaches tried to exploit the immune response to HIV-1 to eliminate infected cells. The team of Dr Zack reported a TCR specific for the SL9 peptide of gag that they were able to express in a lentiviral gene transfer vector to reconstitute anti-HIV $\mathrm{CD}^{+} \mathrm{T}$ cells in HuMice [86] $\square$. In NSG-BLT HuMice, this approach prevented $\mathrm{CD}^{+} \mathrm{T}$ cell deletion and lowered the number of infected cells. Moreover, plasmatic and cellular viral loads were lower in the spleen, thymus and bone marrow compared to control animals [87] $\square$. However, this is a risky strategy in the long-term since improving killing of infected cells may ultimately enhance $\mathrm{CD}^{+} \mathrm{T}$ cell deletion and favors the emergence of mutants able to escape the transgenic TCR. 


\section{Combined strategies}

Indeed, HIV-1 is known for its high mutation rate due to the low fidelity of the retrotranscriptase. It would be probably more productive for gene therapy to target more than one protein to decrease the risk of viral escape. We chose to target two key molecules of the viral entry step using the C46 peptide combined with the P2-CCL5 intrakine. These genes were encoded in a lentiviral gene transfer vector and we showed that they could act in synergy in vitro [62] $\square$. We recently showed that introduction of these two transgenes in human cells protected $\mathrm{CD}^{+} \mathrm{T}^{\mathrm{T}}$ cells against HIV-induced deletion in two different HuMice models, NSG grafted with PBL or modified HSC [63] $\square$. A massive selective advantage for transduced $\mathrm{CD}^{+} \mathrm{T}$ cells was noted, whereas the impact on viral load was only modest, suggesting that the vector might still be improved. Recently, another study with a similar approach using the Cal-1 lentivirus vector, a combination between the C46 peptide and a CCR5 shRNA, showed protection of $\mathrm{CD}^{+} \mathrm{T}$ cells against depletion and a surprising complete control of viral loads in BLT mice [88] $\square$. Combining two fusion inhibitors might be an interesting strategy since the virus will have to lower its fitness to escape both inhibitors [89] $\square$. It is the same motivation to reduce the likelihood of viral escape that has led researchers to assess the combination of ZFN targeting both CCR5 and CXCR4 in $\mathrm{CD}^{+}{ }^{+}$ lymphocytes. Cells negative for CCR5 and CXCR4 became the majority in NSG mice grafted with these modified cells and co-infected with R5 and X4 viruses [90] $\square$. The impact on viral load was not provided.

In the study of Ringpis et al, the authors used a lentiviral vector encoding a CCR5 shRNA combined with a LTR-specific shRNA. This vector confers a selective advantage to $\mathrm{CD} 4^{+} \mathrm{T}$ cells in BLT mice challenged by R5 or X4 tropic HIV strain [91] $\square$. Again, no data on viral loads was provided. Another gene therapy study used h-rhTRIM5 $\alpha$ restriction factor associated with two other 
anti-HIV genes, a shRNA targeting CCR5 and a TAR decoy sequence [92] $\square$. This decoy mimics the TAR viral sequence so that the Tat protein, essential for provirus transcription, would be sequestered away from the HIV-1 provirus. This combination of transgenes therefore target fusion (CCR5 shRNA), uncoating / pre-integration (TRIM5 $\alpha$ ) and post-integration (TAR decoy). A study carried out in NRG mice grafted with transduced human HSC showed protection against $\mathrm{CD}^{+}{ }^{\mathrm{T}}$ cells deletion in blood and spleen for two different viruses (R5 and X4 tropic). Surprisingly, this strategy did not impact the viral load in vivo. Finally, a lentiviral vector carrying a shRNA targeting Tat/rev, a TAR decoy and a CCR5 ribozyme was efficient in the SCID/PBL model [93] $\square$. With this vector, a very modest reduction in viral loads and $\mathrm{CD}^{+} \mathrm{T}$ cell deletion was observed in a clinical trial [94] $\square$. Whether this strategy would select escape variants remains to be investigated.

A recent study combined an entry inhibitor (CCR5 shRNA), a post-transcription inhibitor

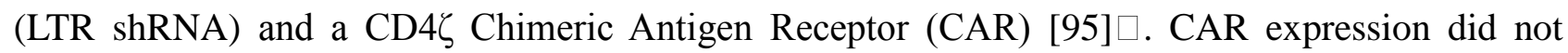
affect hematopoiesis in BLT mice and mice with a high frequency of $\mathrm{CAR}^{+}$cells had a lower viral load and a better preservation of CD4/CD8 T-cell ratios. Although CARs are becoming important tools for cancer immunotherapy, it is not yet clear how well they could be apply to infectious diseases.

\section{Conclusion and future directions}

Humanized mice have taught us that targeting HIV-1 before it enters CD $4^{+} \mathrm{T}$ cells is the most efficient strategy so far. Passive immunization and viral entry inhibitors appear as the most efficient tools to this endeavor. Given the numerous studies with positive results in HuMice exposed here, HIV-1 gene therapy appears as a feasible goal in humans. In 2014, a clinical trial using ZFNs targeting CCR5 in humans obtained similar results than those obtained in the HuMice models, strengthening the potential of these models to predict the efficacy of gene therapy [96] $\square$. Indeed, in 
humans as in mice, modified cells declined more slowly than non-transduced lymphocytes, demonstrating a resistance to HIV-induced deletion. In addition, one patient heterozygous for the CCR5 $\triangle 32$ mutation had an undetectable viral load and all other patients showed a decrease in the amount of viral DNA present in the blood. These results and those of the Berlin patient confirm the therapeutic interest of targeting CCR5 although there is a risk of selecting resistant mutants. That is why different teams targeting the HIV co receptor have added other anti-HIV genes in their construction, such as the $\mathrm{C} 46$ peptide. Based on the data obtained in mouse models, it is expected that the results of the ongoing clinical trial (NCT01734850) using the Cal-1 vector will show protection against HIV-1-induced deletion and an effect on viral load. These results should confirm the interest of targeting the early stages of the infection.

Imperfect as they are, HuMice as models for HIV-1 gene therapy have already brought a great deal to the field. A crucial question remained though: what is the role of a functional immune response on the efficacy of HIV-1 gene therapy? It is striking to note that the most successful HIV-1 gene therapy has been obtained in the BLT model, whereas similar constructs or strategies only partially affected viral replication in other less immunocompetent HuMice models. Thus, the quality of the immune response in BLT mice might have been decisive in the efficiency of the strategy. It will be crucial for the future of HIV-1 gene therapy studies that the BLT model be more widely accessible to the scientific community to define more precisely the impact of a functional immune response on the efficacy of various HIV-1 gene therapy strategies in humans. 


\section{Acknowledgments}

This work was supported by grants from Agence Nationale de la Recherche contre le SIDA

(ANRS). Nicolas Petit was supported by a doctoral fellowship from Fond Pierre Bergé /SIDAction and by the ANRS. We would like to thank Karim Dorgham and Claude Baillou (CIMI-PARIS) for editing the manuscript. The authors declare having no potential conflict of interest. 


\section{References}

[1] Denton PW, García JV. Humanized mouse models of HIV infection. AIDS Rev 2011;13:13548.

[2] Leung C, Chijioke O, Gujer C, Chatterjee B, Antsiferova O, Landtwing V, et al. Infectious diseases in humanized mice. Eur J Immunol 2013;43:2246-54. doi:10.1002/eji.201343815.

[3] Burnett JC, Zaia J a, Rossi JJ. Creating genetic resistance to HIV. Curr Opin Immunol 2012;24:625-32. doi:10.1016/j.coi.2012.08.013.

[4] Gopinath C, Nathar T, Ghosh A, Hickstein D, Remington Nelson E. Contemporary Animal Models For Human Gene Therapy Applications. Curr Gene Ther 2015;15:531-40. doi:10.2174/1566523215666150929110424.

[5] Marsden MD, Zack J a. Studies of retroviral infection in humanized mice. Virology 2015;479-480:297-309. doi:10.1016/j.virol.2015.01.017.

[6] Nazari R, Joshi S. HIV-1 gene therapy at pre-integration and provirus DNA levels. Curr Gene Ther 2009;9:20-5. doi:10.2174/156652309787354658.

[7] McCune JM, Namikawa R, Kaneshima H, Shultz LD, Lieberman M, Weissman IL. The SCID-hu mouse: murine model for the analysis of human hematolymphoid differentiation and function. Science 1988;241:1632-9.

[8] Mosier DE, Gulizia RJ, Baird SM, Wilson DB. Transfer of a functional human immune system to mice with severe combined immunodeficiency. Nature 1988;335:256-9. doi:10.1038/335256a0.

[9] Oettinger MA, Schatz DG, Gorka C, Baltimore D. RAG-1 and RAG-2, adjacent genes that synergistically activate V(D)J recombination. Science 1990;248:1517-23. doi:10.1126/science.2360047.

[10] Schatz DG, Oettinger MA, Baltimore D. The V(D)J recombination activating gene, RAG-1. Cell 1989;59:1035-48.

[11] Ito M, Hiramatsu H, Kobayashi K, Suzue K, Kawahata M, Hioki K, et al. NOD/SCID/gamma(c)(null) mouse: an excellent recipient mouse model for engraftment of human cells. Blood 2002;100:3175-82. doi:10.1182/blood-2001-12-0207.

[12] Shultz LD, Lyons BL, Burzenski LM, Gott B, Chen X, Chaleff S, et al. Human Lymphoid and Myeloid Cell Development in NOD/LtSz-scid IL2R null Mice Engrafted with Mobilized Human Hemopoietic Stem Cells. J Immunol 2005;174:6477-89. doi:10.4049/jimmunol.174.10.6477.

[13] Traggiai E, Chicha L, Mazzucchelli L, Bronz L, Piffaretti J-C, Lanzavecchia A, et al. Development of a human adaptive immune system in cord blood cell-transplanted mice. Science 2004;304:104-7. doi:10.1126/science.1093933. 
[14] Pearson T, Shultz LD, Miller D, King M, Laning J, Fodor W, et al. Non-obese diabeticrecombination activating gene-1 (NOD-Rag1 null) interleukin (IL)-2 receptor common gamma chain (IL2r gamma null) null mice: a radioresistant model for human lymphohaematopoietic engraftment. Clin Exp Immunol 2008;154:270-84. doi:10.1111/j.1365-2249.2008.03753.x.

[15] Lavender KJ, Pang WW, Messer RJ, Duley AK, Race B, Phillips K, et al. BLT-humanized C57BL/6 Rag2-/- $\gamma \mathrm{c}-/-C D 47-/-$ mice are resistant to GVHD and develop B- and T-cell immunity to HIV infection. Blood 2013;122:4013-20. doi:10.1182/blood-2013-06-506949.

[16] Oldenborg P a, Zheleznyak a, Fang YF, Lagenaur CF, Gresham HD, Lindberg FP. Role of CD47 as a marker of self on red blood cells. Science 2000;288:2051-4. doi:10.1126/science.288.5473.2051.

[17] Takenaka K, Prasolava TK, Wang JCY, Mortin-Toth SM, Khalouei S, Gan OI, et al. Polymorphism in Sirpa modulates engraftment of human hematopoietic stem cells. Nat Immunol 2007;8:1313-23. doi:10.1038/ni1527.

[18] Yamauchi T, Takenaka K, Urata S, Shima T, Kikushige Y, Tokuyama T, et al. Polymorphic Sirpa is the genetic determinant for NOD-based mouse lines to achieve efficient human cell engraftment. Blood 2013;121:1316-25. doi:10.1182/blood-2012-06-440354.

[19] Strowig T, Rongvaux A, Rathinam C, Takizawa H, Borsotti C, Philbrick W, et al. Transgenic expression of human signal regulatory protein alpha in Rag2-/-gamma(c)-/- mice improves engraftment of human hematopoietic cells in humanized mice. Proc Natl Acad Sci U S A 2011;108:13218-23. doi:10.1073/pnas.1109769108.

[20] Legrand N, Huntington ND, Nagasawa M, Bakker AQ, Schotte R, Strick-Marchand H, et al. Functional CD47/signal regulatory protein alpha (SIRP(alpha)) interaction is required for optimal human T- and natural killer- (NK) cell homeostasis in vivo. Proc Natl Acad Sci U S A 2011;108:13224-9. doi:10.1073/pnas.1101398108.

[21] King MA, Covassin L, Brehm MA, Racki W, Pearson T, Leif J, et al. Human peripheral blood leucocyte non-obese diabetic-severe combined immunodeficiency interleukin-2 receptor gamma chain gene mouse model of xenogeneic graft- versus -host-like disease and the role of host major histocompatibility complex. Clin Exp Immunol 2009;157:104-18. doi:10.1111/j.1365-2249.2009.03933.x.

[22] Racki WJ, Covassin L, Brehm M, Pino S, Ignotz R, Dunn R, et al. NOD-scid IL2rynull Mouse Model of Human Skin Transplantation and Allograft Rejection. Transplantation 2010;89:527-36. doi:10.1097/TP.0b013e3181c90242.

[23] Mosier DE, Gulizia RJ, Baird SM, Wilson DB, Spector DH, Spector SA. Human immunodeficiency virus infection of human-PBL-SCID mice. Science 1991;251:791-4.

[24] Marodon G, Desjardins D, Mercey L, Baillou C, Parent P, Manuel M, et al. High diversity of the immune repertoire in humanized NOD.SCID.gamma c-/- mice. Eur J Immunol 2009;39:2136-45. doi:10.1002/eji.200939480. 
[25] Watanabe S, Terashima K, Ohta S, Horibata S, Yajima M, Shiozawa Y, et al. Hematopoietic stem cell-engrafted NOD/SCID/IL2R \{ gamma $\}$ null mice develop human lymphoid systems and induce long-lasting HIV-1 infection with specific humoral immune responses. Blood 2007;109:212-8. doi:10.1182/blood-2006-04-017681.

[26] Kumar P, Ban H-S, Kim S-S, Wu H, Pearson T, Greiner DL, et al. T cell-specific siRNA delivery suppresses HIV-1 infection in humanized mice. Cell 2008;134:577-86. doi:10.1016/j.cell.2008.06.034.

[27] Walker JE, Chen RX, McGee J, Nacey C, Pollard RB, Abedi M, et al. Generation of an HIV1 resistant immune system with CD34+ HSCs transduced with a triple combination anti-HIV lentiviral vector. J Virol 2012. doi:10.1128/jvi.06300-11.

[28] Gorantla S, Makarov E, Finke-Dwyer J, Gebhart CL, Domm W, Dewhurst S, et al. CD8+ cell depletion accelerates HIV-1 immunopathology in humanized mice. J Immunol 2010;184:7082-91. doi:10.4049/jimmunol.1000438.

[29] Petit NY, Lambert-Niclot S, Marcelin A-G, Garcia S, Marodon G. HIV Replication Is Not Controlled by CD8+ T Cells during the Acute Phase of the Infection in Humanized Mice. PLoS One 2015;10:e0138420. doi:10.1371/journal.pone.0138420.

[30] Berges BK, Akkina SR, Folkvord JM, Connick E, Akkina R. Mucosal transmission of R5 and X4 tropic HIV-1 via vaginal and rectal routes in humanized Rag2-/- gammac -/- (RAG-hu) mice. Virology 2008;373:342-51. doi:10.1016/j.virol.2007.11.020.

[31] Akkina R, Berges BK, Palmer BE, Remling L, Neff CP, Kuruvilla J, et al. Humanized Rag1/- gc-/- mice support multilineage hematopoiesis and are susceptible to HIV-1 infection via systemic and vaginal routes. PLoS One 2011;6:1-8. doi:10.1371/journal.pone.0020169.

[32] Neff CP, Ndolo T, Tandon A, Habu Y, Akkina R. Oral pre-exposure prophylaxis by antiretrovirals raltegravir and maraviroc protects against HIV-1 vaginal transmission in a humanized mouse model. PLoS One 2010;5:e15257 doi:10.1371/journal.pone.0015257. doi:10.1371/journal.pone.0015257.

[33] Hofer U, Baenziger S, Heikenwalder M, Schlaepfer E, Gehre N, Regenass S, et al. RAG2-/gamma(c)-/- mice transplanted with CD34+ cells from human cord blood show low levels of intestinal engraftment and are resistant to rectal transmission of human immunodeficiency virus. J Virol 2008;82:12145-53. doi:10.1128/JVI.01105-08.

[34] Lan P, Tonomura N, Shimizu A, Wang S, Yang Y-G. Reconstitution of a functional human immune system in immunodeficient mice through combined human fetal thymus/liver and CD34+ cell transplantation. Blood 2006;108:487-92. doi:10.1182/blood-2005-11-4388.

[35] Melkus MW, Estes JD, Padgett-Thomas A, Gatlin J, Denton PW, Othieno FA, et al. Humanized mice mount specific adaptive and innate immune responses to EBV and TSST-1. Nat Med 2006;12:1316-22. doi:10.1038/nm1431.

[36] Brainard DM, Seung E, Frahm N, Cariappa A, Bailey CC, Hart WK, et al. Induction of 
Robust Cellular and Humoral Virus-Specific Adaptive Immune Responses in Human Immunodeficiency Virus-Infected Humanized BLT Mice. J Virol 2009;83:7305-21. doi:10.1128/jvi.02207-08.

[37] Greenblatt MB, Vrbanac V, Vbranac V, Tivey T, Tsang K, Tager AM, et al. Graft versus host disease in the bone marrow, liver and thymus humanized mouse model. PLoS One 2012;7:e44664. doi:10.1371/journal.pone.0044664.

[38] Denton PW, Garcia JV. Mucosal HIV-1 transmission and prevention strategies in BLT humanized mice. Trends Microbiol 2012;20:268-74. doi:10.1016/j.tim.2012.03.007.

[39] Daar ES, Li XL, Moudgil T, Ho DD. High concentrations of recombinant soluble CD4 are required to neutralize primary human immunodeficiency virus type 1 isolates. Proc Natl Acad Sci U S A 1990;87:6574-8. doi:10.1073/pnas.87.17.6574.

[40] Gardner MR, Kattenhorn LM, Kondur HR, Von Schaewen M, Dorfman T, Chiang JJ, et al. AAV-expressed eCD4-Ig provides durable protection from multiple SHIV challenges. Nature 2015. doi:10.1038/nature14264.

[41] Lim JK, Glass WG, McDermott DH, Murphy PM. CCR5: no longer a "good for nothing" gene--chemokine control of West Nile virus infection. Trends Immunol 2006;27:308-12. doi:10.1016/j.it.2006.05.007.

[42] Samson M, Libert F, Doranz BJ, Rucker J, Liesnard C, Farber CM, et al. Resistance to HIV-1 infection in caucasian individuals bearing mutant alleles of the CCR-5 chemokine receptor gene. Nature 1996;382:722-5. doi:10.1038/382722a0.

[43] Gulick RM, Lalezari J, Goodrich J, Clumeck N, DeJesus E, Horban A, et al. Maraviroc for previously treated patients with R5 HIV-1 infection. N Engl J Med 2008;359:1429-41. doi:10.1056/NEJMoa0803152.

[44] Allers K, Hütter G, Hofmann J, Loddenkemper C, Rieger K, Thiel E, et al. Evidence for the cure of HIV infection by CCR5 $\Delta 32 / \Delta 32$ stem cell transplantation. Blood 2011;117:2791-9. doi:10.1182/blood-2010-09-309591.

[45] Hutter G, Nowak D, Mossner M, Ganepola S, Mussig A, Allers K, et al. Long-Term Control of HIV by CCR5 Delta32/Delta32 Stem-Cell Transplantation. N Engl J Med 2009;360:6928. doi:10.1056/NEJMoa0802905.

[46] Perez EE, Wang J, Miller JC, Jouvenot Y, Kim KA, Liu O, et al. Establishment of HIV-1 resistance in CD4+ T cells by genome editing using zinc-finger nucleases. Nat Biotechnol 2008;26:808-16. doi:10.1038/nbt1410.

[47] Holt N, Wang J, Kim K, Friedman G, Wang X, Taupin V, et al. Human hematopoietic stem/progenitor cells modified by zinc-finger nucleases targeted to CCR5 control HIV-1 in vivo. Nat Biotechnol 2010;28:839-47. doi:10.1038/nbt.1663.

[48] Yi G, Choi JG, Bharaj P, Abraham S, Dang Y, Kafri T, et al. CCR5 Gene Editing of Resting CD4(+) T Cells by Transient ZFN Expression From HIV Envelope Pseudotyped 
Nonintegrating Lentivirus Confers HIV-1 Resistance in Humanized Mice. Mol Ther Nucleic Acids 2014;3:e198. doi:10.1038/mtna.2014.52.

[49] Wilen CB, Wang J, Tilton JC, Miller JC, Kim KA, Rebar EJ, et al. Engineering HIV-resistant human CD4+ T cells with CXCR4-specific zinc-finger nucleases. PLoS Pathog 2011;7:e1002020. doi:10.1371/journal.ppat.1002020.

[50] Yuan J, Wang J, Crain K, Fearns C, Kim KA, Hua KL, et al. Zinc-finger nuclease editing of human cxcr4 promotes HIV-1 CD4(+) T cell resistance and enrichment. Mol Ther 2012;20:849-59. doi:10.1038/mt.2011.310.

[51] Mock U, Machowicz R, Hauber I, Horn S, Abramowski P, Berdien B, et al. mRNA transfection of a novel TAL effector nuclease (TALEN) facilitates efficient knockout of HIV co-receptor CCR5. Nucleic Acids Res 2015;43:5560-71. doi:10.1093/nar/gkv469.

[52] Wang W, Ye C, Liu J, Zhang D, Kimata JT, Zhou P. CCR5 gene disruption via lentiviral vectors expressing Cas9 and single guided RNA renders cells resistant to HIV-1 infection. PLoS One 2014;9:e115987. doi:10.1371/journal.pone.0115987.

[53] Schleifman EB, Bindra R, Leif J, del Campo J, Rogers F a, Uchil P, et al. Targeted disruption of the CCR5 gene in human hematopoietic stem cells stimulated by peptide nucleic acids. Chem Biol 2011;18:1189-98. doi:10.1016/j.chembiol.2011.07.010.

[54] Schleifman EB, McNeer NA, Jackson A, Yamtich J, Brehm M a, Shultz LD, et al. Sitespecific Genome Editing in PBMCs With PLGA Nanoparticle-delivered PNAs Confers HIV1 Resistance in Humanized Mice. Mol Ther Nucleic Acids 2013;2:e135. doi:10.1038/mtna.2013.59.

[55] Qin X-F, An DS, Chen ISY, Baltimore D. Inhibiting HIV-1 infection in human T cells by lentiviral-mediated delivery of small interfering RNA against CCR5. Proc Natl Acad Sci U S A 2003;100:183-8. doi:10.1073/pnas.232688199.

[56] Kim S-S, Peer D, Kumar P, Subramanya S, Wu H, Asthana D, et al. RNAi-mediated CCR5 silencing by LFA-1-targeted nanoparticles prevents HIV infection in BLT mice. Mol Ther 2010;18:370-6. doi:10.1038/mt.2009.271.

[57] Shimizu S, Hong P, Arumugam B, Pokomo L, Boyer J, Koizumi N, et al. A highly efficient short hairpin RNA potently down-regulates CCR5 expression in systemic lymphoid organs in the hu-BLT mouse model. Blood 2010;115:1534-44. doi:10.1182/blood-2009-04-215855.

[58] Myburgh R, Ivic S, Pepper MS, Gers-Huber G, Li D, Audigé A, et al. Lentivector knockdown of CCR5 in hematopoietic stem cells confers functional and persistent HIV-1 resistance in humanized mice. J Virol 2015;89:6761-72. doi:10.1128/JVI.00277-15.

[59] Shimizu S, Ringpis G-E, Marsden MD, Cortado R V, Wilhalme HM, Elashoff D, et al. RNAi-Mediated CCR5 Knockdown Provides HIV-1 Resistance to Memory T Cells in Humanized BLT Mice. Mol Ther Nucleic Acids 2015;4:e227. doi:10.1038/mtna.2015.3.

[60] Swan CH, Bühler B, Steinberger P, Tschan MP, Barbas CF, Torbett BE. T-cell protection and 
enrichment through lentiviral CCR5 intrabody gene delivery. Gene Ther 2006;13:1480-92. doi:10.1038/sj.gt.3302902.

[61] Hartley O, Dorgham K, Perez-Bercoff D, Cerini F, Heimann A, Gaertner H, et al. Human immunodeficiency virus type 1 entry inhibitors selected on living cells from a library of phage chemokines. J Virol 2003;77:6637-44. doi:10.1128/JVI.77.12.6637-6644.2003.

[62] Petit N, Dorgham K, Levacher B, Burlion A, Gorochov G, Marodon G. Targeting Both Viral and Host Determinants of Human Immunodeficiency Virus Entry, Using a New Lentiviral Vector Coexpressing the T20 Fusion Inhibitor and a Selective CCL5 Intrakine. Hum Gene Ther Methods 2014;25:232-40. doi:10.1089/hgtb.2014.034.

[63] Petit NY, Baillou C, Burlion A, Dorgham K, Levacher B, Amiel C, et al. Gene transfer of two entry inhibitors protects CD4(+) T cell from HIV-1 infection in humanized mice. Gene Ther 2015. doi:10.1038/gt.2015.101.

[64] Kilby JM, Hopkins S, Venetta TM, DiMassimo B, Cloud GA, Lee JY, et al. Potent suppression of HIV-1 replication in humans by T-20, a peptide inhibitor of gp41-mediated virus entry. Nat Med 1998;4:1302-7. doi:10.1038/3293.

[65] Egelhofer M, Brandenburg G, Martinius H, Schult-Dietrich P, Melikyan G, Kunert R, et al. Inhibition of Human Immunodeficiency Virus Type 1 Entry in Cells Expressing gp41Derived Peptides. J Virol 2004;78:568-75.

[66] Kimpel J, Braun SE, Qiu G, Wong FE, Conolle M, Schmitz JE, et al. Survival of the fittest: positive selection of CD4+ T cells expressing a membrane-bound fusion inhibitor following HIV-1 infection. PLoS One 2010;5:e12357. doi:10.1371/journal.pone.0012357.

[67] Stremlau M, Owens CM, Perron MJ, Kiessling M, Autissier P, Sodroski J. The cytoplasmic body component TRIM5alpha restricts HIV-1 infection in Old World monkeys. Nature 2004;427:848-53. doi:10.1038/nature02343.

[68] Stremlau M, Perron M, Lee M, Li Y, Song B, Javanbakht H, et al. Specific recognition and accelerated uncoating of retroviral capsids by the TRIM5alpha restriction factor. Proc Natl Acad Sci U S A 2006;103:5514-9. doi:10.1073/pnas.0509996103.

[69] Anderson J, Akkina R. Human immunodeficiency virus type 1 restriction by human-rhesus chimeric tripartite motif 5alpha (TRIM 5alpha) in CD34(+) cell-derived macrophages in vitro and in T cells in vivo in severe combined immunodeficient (SCID-hu) mice transplanted with human fe. Hum Gene Ther 2008;19:217-28. doi:10.1089/hum.2007.108.

[70] Llano M, Saenz DT, Meehan A, Wongthida P, Peretz M, Walker WH, et al. An essential role for LEDGF/p75 in HIV integration. Science 2006;314:461-4. doi:10.1126/science.1132319.

[71] Vets S, Kimpel J, Volk A, De Rijck J, Schrijvers R, Verbinnen B, et al. Lens epitheliumderived growth factor/p75 qualifies as a target for HIV gene therapy in the NSG mouse model. Mol Ther 2012;20:908-17. doi:10.1038/mt.2012.6.

[72] ter Brake O, Legrand N, von Eije KJ, Centlivre M, Spits H, Weijer K, et al. Evaluation of 
safety and efficacy of RNAi against HIV-1 in the human immune system (Rag-2(-/)gammac(-/-)) mouse model. Gene Ther 2009;16:148-53. doi:10.1038/gt.2008.124.

[73] Herrera-Carrillo E, Berkhout B. The impact of HIV-1 genetic diversity on the efficacy of a combinatorial RNAi-based gene therapy. Gene Ther 2015. doi:10.1038/gt.2015.11.

[74] Sarkar I, Hauber I, Hauber J, Buchholz F. HIV-1 proviral DNA excision using an evolved recombinase. Science (80- ) 2007;316:1912-5. doi:10.1126/science.1141453.

[75] Hauber I, Hofmann-Sieber H, Chemnitz J, Dubrau D, Chusainow J, Stucka R, et al. Highly significant antiviral activity of HIV-1 LTR-specific tre-recombinase in humanized mice. PLoS Pathog 2013;9:e1003587. doi:10.1371/journal.ppat.1003587.

[76] Ebina H, Misawa N, Kanemura Y, Koyanagi Y. Harnessing the CRISPR/Cas9 system to disrupt latent HIV-1 provirus. Sci Rep 2013;3:2510. doi:10.1038/srep02510.

[77] Ebina H, Kanemura Y, Misawa N, Sakuma T, Kobayashi T, Yamamoto T, et al. A high excision potential of TALENs for integrated DNA of HIV-based lentiviral vector. PLoS One 2015;10:e0120047. doi:10.1371/journal.pone.0120047.

[78] Doitsh G, Galloway NLK, Geng X, Yang Z, Monroe KM, Zepeda O, et al. Cell death by pyroptosis drives CD4 T-cell depletion in HIV-1 infection. Nature 2014;505:509-14. doi:10.1038/nature12940.

[79] Horwitz J a, Halper-Stromberg A, Mouquet H, Gitlin AD, Tretiakova A, Eisenreich TR, et al. HIV-1 suppression and durable control by combining single broadly neutralizing antibodies and antiretroviral drugs in humanized mice. Proc Natl Acad Sci U S A 2013;110:16538-43. doi:10.1073/pnas.1315295110.

[80] Klein F, Halper-Stromberg A, Horwitz JA, Gruell H, Scheid JF, Bournazos S, et al. HIV therapy by a combination of broadly neutralizing antibodies in humanized mice. Nature 2012;492:118-22. doi:10.1038/nature11604.

[81] Lewis AD, Chen R, Montefiori DC, Johnson PR, Clark KR. Generation of Neutralizing Activity against Human Immunodeficiency Virus Type 1 in Serum by Antibody Gene Transfer. J Virol 2002;76:8769-75. doi:10.1128/JVI.76.17.8769-8775.2002.

[82] Balazs AB, Chen J, Hong CM, Rao DS, Yang L, Baltimore D. Antibody-based protection against HIV infection by vectored immunoprophylaxis. Nature 2012;481:81-4. doi:10.1038/nature10660.

[83] Balazs AB, Ouyang Y, Hong CM, Chen J, Nguyen SM, Rao DS, et al. Vectored immunoprophylaxis protects humanized mice from mucosal HIV transmission. Nat Med 2014;20:296-300. doi:10.1038/nm.3471.

[84] Liu S, Jackson A, Beloor J, Kumar P, Sutton RE. Adenovirus-Vectored Broadly Neutralizing Antibodies Directed Against gp120 Prevent Human Immunodeficiency Virus Type 1 Acquisition in Humanized Mice. Hum Gene Ther 2015;26:622-34. doi:10.1089/hum.2014.146. 
[85] Joseph A, Zheng JH, Chen K, Dutta M, Chen C, Stiegler G, et al. Inhibition of in vivo HIV infection in humanized mice by gene therapy of human hematopoietic stem cells with a lentiviral vector encoding a broadly neutralizing anti-HIV antibody. J Virol 2010;84:664553. doi:10.1128/JVI.02339-09.

[86] Kitchen SG, Bennett M, Galić Z, Kim J, Xu Q, Young A, et al. Engineering antigen-specific $\mathrm{T}$ cells from genetically modified human hematopoietic stem cells in immunodeficient mice. PLoS One 2009;4:e8208. doi:10.1371/journal.pone.0008208.

[87] Kitchen SG, Levin BR, Bristol G, Rezek V, Kim S, Aguilera-Sandoval C, et al. In vivo suppression of HIV by antigen specific T cells derived from engineered hematopoietic stem cells. PLoS Pathog 2012;8:e1002649. doi:10.1371/journal.ppat.1002649.

[88] Burke BP, Levin BR, Zhang J, Sahakyan A, Boyer J, Carroll M V, et al. Engineering Cellular Resistance to HIV-1 Infection In Vivo Using a Dual Therapeutic Lentiviral Vector. Mol Ther Acids 2015;4:e236. doi:10.1038/mtna.2015.10.

[89] von Laer D, Hasselmann S, Hasselmann K. Gene therapy for HIV infection: what does it need to make it work? J Gene Med 2006;8:658-67. doi:10.1002/jgm.908.

[90] Didigu C a, Wilen CB, Wang J, Duong J, Secreto AJ, Danet-Desnoyers G a, et al. Simultaneous zinc-finger nuclease editing of the HIV coreceptors ccr5 and cxcr4 protects CD4+ T cells from HIV-1 infection. Blood 2014;123:61-9. doi:10.1182/blood-2013-08521229.

[91] Ringpis G-EE, Shimizu S, Arokium H, Camba-Colón J, Carroll M V, Cortado R, et al. Engineering HIV-1-Resistant T-Cells from Short-Hairpin RNA-Expressing Hematopoietic Stem/Progenitor Cells in Humanized BLT Mice. PLoS One 2012;7:e53492. doi:10.1371/journal.pone.0053492.

[92] Walker JE, Chen RX, McGee J, Nacey C, Pollard RB, Abedi M, et al. Generation of an HIV1-resistant immune system with CD34(+) hematopoietic stem cells transduced with a triplecombination anti-HIV lentiviral vector. J Virol 2012;86:5719-29. doi:10.1128/JVI.06300-11.

[93] Anderson J, Li M-J, Palmer B, Remling L, Li S, Yam P, et al. Safety and efficacy of a lentiviral vector containing three anti-HIV genes--CCR5 ribozyme, tat-rev siRNA, and TAR decoy--in SCID-hu mouse-derived T cells. Mol Ther 2007;15:1182-8. doi:10.1038/sj.mt.6300157.

[94] DiGiusto DL, Krishnan A, Li L, Li H, Li S, Rao A, et al. RNA-based gene therapy for HIV with lentiviral vector-modified CD34(+) cells in patients undergoing transplantation for AIDS-related lymphoma. Sci Transl Med 2010;2:36ra43. doi:10.1126/scitranslmed.3000931.

[95] Zhen A, Kamata M, Rezek V, Rick J, Levin B, Kasparian S, et al. HIV-specific Immunity Derived From Chimeric Antigen Receptor-engineered Stem Cells. Mol Ther 2015;23:135867. doi:10.1038/mt.2015.102.

[96] Tebas P, Stein D, Tang WW, Frank I, Wang SQ, Lee G, et al. Gene Editing of CCR5 in 
Autologous CD4 T Cells of Persons Infected with HIV. N Engl J Med 2014;370:901-10. doi:10.1056/NEJMoa1300662. 


\begin{tabular}{|c|c|c|c|}
\hline Strain & $\begin{array}{c}\text { Genetic } \\
\text { background }\end{array}$ & Mutations & Ref \\
\hline CB.17/SCID & CB.17 & Prkdc ${ }^{\text {scid }}$ & {$[7,8] \square$} \\
\hline NSG & NOD & $\operatorname{Prkdc}^{\mathrm{scid}}-\mathrm{Il} 2 \mathrm{rg}^{\mathrm{tm} 1 \mathrm{Wjl}}$ & {$[12] \square$} \\
\hline NOG & NOD & Prkdc ${ }^{\text {scid }}-I 12 \operatorname{rg}^{\text {tm1Sug }}$ & {$[11] \square$} \\
\hline NRG & NOD & RAG1-Il2rg ${ }^{\text {tm1Sug }}$ & {$[14] \square$} \\
\hline $\mathrm{BRG}$ & $\mathrm{BALB} / \mathrm{c}$ & RAG2-Il2rg ${ }^{\text {tm1Sug }}$ & {$[13] \square$} \\
\hline BRGS & $\mathrm{BALB} / \mathrm{c}$ & RAG2-Il2 $\mathrm{rg}^{\mathrm{tm} 1 \mathrm{Sug}}-\mathrm{SIRP} \alpha^{\mathrm{NOD}}$ & {$[19] \square$} \\
\hline $\mathrm{TKO}$ & C57BL/6 & RAG2-Il2rg ${ }^{\text {tm1Wjl }}$ CD47 ${ }^{-/-}$ & {$[15] \square$} \\
\hline
\end{tabular}

Table 1: a summary of immunodeficient mice strains, genetic background and associated mutations used to generate humanized mice. NS, NOD.SCID; NSG, NOD.SCID.gc-/-; NOG, NOD.SCIDgc-/-; NRG, NOD.RAG.gc-/-; BRG; BALB/c.RAG.gc-/-; BRGS, BALB.RAG.gc-/-.SIRPa; TKO; Triple knock out. The origin of the mutations are indicated as exposant. 


\begin{tabular}{|c|c|c|}
\hline STRATEGIES & MOUSE MODEL & REF \\
\hline \multicolumn{3}{|l|}{ VIRUS ENTRY } \\
\hline eCD4-Ig & NSG & {$[40] \square$} \\
\hline shRNA CCR5 & NSG & {$[56-58] \square$} \\
\hline CCR5 ZFN & NSG/NOG & {$[46,47] \square$} \\
\hline CXCR4 ZFN & NSG & {$[49,50] \square$} \\
\hline CCR5 Intrabody & NS & {$[60] \square$} \\
\hline C46 peptide & NOG & {$[66] \square$} \\
\hline \multicolumn{3}{|l|}{ DECAPSIDATION, PRE- AND POST-INTEGRATION } \\
\hline LEDGF/p75 & NSG & {$[71] \square$} \\
\hline \multicolumn{3}{|l|}{ PROVIRUS TRANSCRIPTION } \\
\hline Tre Recombinase & BRG & {$[75] \square$} \\
\hline \multicolumn{3}{|l|}{ PASSIVE IMMUNIZATION AND CYTOTOXICITY ACTIVITY } \\
\hline Neutralizing Ab against gp41/gp120/gp160 & NRG/NSG & {$[79,80,82-85] \square$} \\
\hline TCR (gag epitope) & NSG & {$[87] \square$} \\
\hline \multicolumn{3}{|l|}{ COMBINED STRATEGIES } \\
\hline shRNA CCR5, Tar decoy, Human/ Rhesus chimeric TRIM5 $\alpha$ & NRG & {$[92] \square$} \\
\hline CCR5 Ribozyme, tat/rev siRNA, Tar decoy & SCID & {$[93] \square$} \\
\hline shRNA CCR5, shRNA LTR & NSG & {$[91] \square$} \\
\hline shRNA CCR5, C46 peptide & NSG & {$[88] \square$} \\
\hline P2-CCL5 intrakine, C46 peptide & NSG & {$[63] \square$} \\
\hline CAR (gp120), shRNA CCR5, shRNA LTR & NSG & {$[95] \square$} \\
\hline
\end{tabular}

Table 2: Efficient anti-HIV-1 gene strategies achieved in humanized mice. Shown are the most significant results obtained with recent strains of immunodeficient mice in which gene transfer into mature or immature $\mathrm{T}$ cells has shown some efficacy. Refer to Table 1 for mouse model abbreviations. 